\title{
The Business Culture In The Activity Of The Commercial Bank In Vietnam Recently
}

\author{
Vu Tien Duc \\ Banking University of Ho Chi Minh City - Postgraduate at University of Social Sciences \\ and Humanities, Vietnam National University Ho Chi Minh City,Vietnam \\ Email:ducvt@buh.edu.vn
}

\section{Summaries:}

Before the fourth Industrial Revolution, business activities of banks in general and commercial banks in specific were changing and adapting with the era. The recently suitable development of commercial banks in Vietnam always aims at people, to the culture as a motivation, to basic, to the inner strength of human and social development. Thus, the secret in the suitable development of the commercial bank recently in Vietnam is directly related to the cultural factor, there is the business culture. The aspect of the business culture is a mode of suitable business activities. Otherwise, these are the resources for the business development of the commercial bank in Vietnam. With the group of theoretical research, the group of reality research, based on approaching culture, the article is analyzing clearly the basics of the business culture in Vietnam recently. From there, the article points to the fundamental solution to developing the business culture in the commercial bank system in Vietnam.

Keywords:

Culture, business culture, bank, commercial bank, Vietnam.

\section{Entering}

The currency, the bank, is an important field, systematic, and has a great influence on macroeconomics stability. In Vietnam, the banking industry always exposes the role of the main systematization for the national economy. mobilizing and sharing financial resources and the development of economy-social in the country. During 35 years of innovation, Banking industry in general, there is a commercial bank (NHTM) in specific, always building, complete regulations, policies, and step-by-step stability on the bank system from the first level to the second level. Gradually reasonable with the market economy and deep international integration. Step-by-step development, separating management, executing policy on currency in National Bank to provide the credit, Banking services of the organized credit system, to ensure reasonable regulation, the international standard and perform better the role in the economy.

In the development of society, the demand for the capital of the economy is increasing, no organization can satisfy. Just the bank-organization plays the intermediate to run, to distribute capital to help the economic development.

The role of the commercial bank is also a tool to regulate the international macroeconomics, the intermediate between the business and market, to connect national 
finance to international finance. to obtain achievements and results is started by the diversity of the cause. There, we have to mention the keys of the suitable development of the NHTM system in Vietnam has the position, an important role of the cultural factor. Because recognizing the cultural development in the relationship with economic growth, is not simple. This is an argument in many fields of economics, politics, culture,... Today, in the intense development of knowledge, the exploiting of culture, the main one is the reality occurring the crisis, unemployment and social class divisions are increasing in capitalist countries. The GDP is not all of the development. Thus, do not use GDP as a measurement of development, instead, the culture actually is measurable for the suitable development in general, in this, having the suitable development of the NHTM system.

\section{Researching Questions:}

Question 1: What are the fundamental features of the business culture in the commercial bank recently?

Question 2: What are the solutions to developing a business culture in the commercial bank system in Vietnam recently?

\section{Researching Purposes:}

The purpose of the article is to analyze the specifics of the fundamental features of the business culture in the commercial bank. From there, the article points to the solutions to developing the business culture in the commercial bank in Vietnam recently.

\section{Researching Methods:}

The article uses secondary data from many resources and results of commercial banks via the information; data is looked up via the report, the article, and the argument of experts. the operation manager in fields related to the information of the article. Furthermore, the article also synthesizes methods of the research such as inductive and deductive methods, logic and history, comparison, comparing the reasoning with reality.

\section{Content}

The fundamental features of business culture in the commercial bank in Vietnam recently.

Today, the terminology " business culture" is a phrase used broadly and usually recently. Especially, when the market economy is admitted and increased - the entrepreneur and the business are honored, the tendency of the integration becomes a center of the target of countries in the World, the business culture is essential, contributing to the win or loss of any business, including NHTM. The business culture could know " all the factors of the culture are filtered by business entity, creation, to use and express in business operations to create the features of the business entity. operating reality and business of the NHTM system, we can see "signs" quite clearly in activities of running an NHTM business. This point is present via human resources and to put the position, organizational structure of human resources, and the conversation from the employee to managing the business, which the business entity applies efficiently. Of course, business operations do not take the value of culture as an aim directly, business intelligently, from the first of capital, organized operations, the strategy of the business, marketer, service, business premises, business field,....expressing important values, the business also manifests culture with people. the factors combine including Business philosophy (the ideas guide the business 
operation) and business ethics (regulations, the standard of the adjusted rate, guide, controlling behavior of business). The specific business culture could relate to habit, community, national, hereditary,....

In the integration and competition recently, NHTM confirmed step-by-step the position and an important role in the national business. NHTM is intermediate finance running in sectoral currency, which is closely related to the development of all sectors in national finance. Customers of a bank are members of society if they have demand, the activity of the bank is related to sectors of life, economy, society. The NHTM system is a significant proportion in the intermediate activity of exchange currency, providing a diversity of financial services and supply services before, aiming for the policy of national currency. With the position and an important role to ensure the NHTM system develops suitable in the "limited" world, the focus on business culture in the activity of NHTM is essential. Contributing not only development of suitableness but also influence to the suitable development of society. The business culture in NHTM has similarities with features in general of the business culture, but due to the specific activity in the sector of currency. Thus, the fundamental imply features such as:

Firstly, each bank needs to create a unique business philosophy. Banks as well as NHTM in particular are not only the fundraisers but also the lenders to customers. Due to this position of intermediary, the mission of NHTM is "connecting the demand of different money in the economy", from which the business strategy of each NHTM is established, combined with suitable socio-economic conditions in each situation in order to create the best conditions for customers to deposit and borrow money. The business strategy of each NHTM is different depending on the business environment each time. However, banks must ensure the main content of strategy, including making efforts to improve the best serving product for the demand of customers; having supporting services for customers to effectively explore the products provided; creating facilities toward improving procedures to better meet the needs of customers.

Regarding the NHTM system, the business philosophy contains three key factors. The first one is the business goals. The second one is the mode of action and the relationship of the enterprise with the socio-economic environment while the third one is the general obligations of the enterprise and the principles of conduct of its members. All of them are the code of conduct, business style as well as the most common legal and ethical value of business culture. Thus, the business philosophy plays an important role in all over activities of a bank because it is a system of principles, missions, goals, strategies, which can orientate the operating process of the bank. Building the right, effective as well as positive business philosophy is the best launcher for sustainably developing the business culture, which is the power and the motivation for stably developing an enterprise.

Secondly, business ethics need to be built. With the aim of sustainably growing in the current integration context, all NHTMs should pay attention to construct moral standards for business. Forming regulations on ethical standards of employees should be focused on since the bank was newly established. Ethical principles, forms of reward, and compensations are some of many contents of the banking business ethics, which has the 
effect of adjusting daily activities of the bank, deterring the staff from cultivating ethics to help form persons who are devoted to the common cause in a disciplined and culturally well-behaved organization. In the new context, each bank has many regulations about standards of the banking staff toward a specific goal that the banking staff must have 'Mind - Reach - Great" and other criteria supporting such as: having an optimistic lifestyle and striving spirit, motivating growth, etc.

Some fundamental measures help develop a business culture in the NHTM system in Vietnam currently

The NHTM system increasingly plays a large and long-term role in the economic development of the country. Thus, finding the correct answer for building the business culture in many NHTMs is really necessary, which requires the efforts, determinations of the NHTM system and relevant agencies. In our opinion, in the short-term, at this time, developing the business culture in the NHTM system should focus on many fundamental and feasible measures, including:

Firstly, it is necessary to construct a favorable business environment, a business culture, a team of cultural entreneuphers as well as raise social awareness of the business culture. Regarding the NHTM system, forming a model of the business culture positively as the foundation for the stable development of the bank.

Secondly, the core of the business culture is the ethics of the salesman. Therefore, it is necessary to train the banking employees which are both talented and virtuous and raise awareness of the business culture for the other staff of the bank.

Thirdly, regarding state management, it is essential to accelerate administrative reform toward democracy, clearness, professionalism and modernity. The implementing cadres should have cultural behavior with citizens and enterprises. At the same time, the state agencies set up a close relationship with the Vietnam Banking Association, assisting the bank with matters related to the brand, intellectual property and the connection in the area.

Fourth, Approaching " to locate" criteria to build the fundamental structure for bank staff. frequently make an examination of strengths and weaknesses while assessing the business culture to remind the bank staff of the responsibilities and obligations of their own individual in society. Otherwise, promoting the propaganda, popularizing the law and specialized knowledge for members in the bank.

\section{Conclusion}

In the period of last time, although influenced and extremely impacted from the Covid-19 pandemics. but, the Banking industry permits and deploys policies, creation, the high proportion to execution, running the market of currency efficiently and activity safely. suitable, contributing to control inflation, suitable macroeconomics and creating the condition of the invest operation, business operations, to adapt to the context of the Covid-19 pandemics. Adapting the innovation and the integration into the area and the world, organizing credit systems in general, the commercial bank in specific are step-bystep developments of the type, flourishing the capital and the property. Step-by-step innovations, apply the high models of executives, Morden, approaching the standard and international rules, doing better and efficient mobilization and furnishing the capital, 
services of the bank in the economy. Vietnam is developing, the context of opportunities and challenges are intertwined in present, constructing and promote the value of the business culture are essential, contributing the resources to retain customers, the relationship with the potential customer and increasing suitableness of the commercial bank system. the main one is the business culture is an essential factor. showing the significant, influence on the existence and suitable developments of the commercial bank system in Vietnam recently. Research has been done and analyzed fundamental features of the business culture in the commercial bank in Vietnam recently. From there, pointing to fundamental solutions to developing the business culture in the commercial bank in Vietnam recently. the limit of the research does not point and dig into researching the factors of the business culture for the Joint-stock commercial bank in Vietnam recently.

\section{Acknowledgement}

I would like to take this opportunity to express my warm thanks to Board of editors, my family, colleagues and brother in assisting convenient conditions for my research paper.

\section{REFERENCES}

1. Daniel R. Denison. (1990). Corporate culture and Organizational Effectiveness. New York: John Wiley \& Sons.

2. Edgar H.Schein (2004). Organizational Culture and Leadership.3rd de. San Francisco: Wiley Publishing.

3. Hue, H. T. and Ha, D. T. (2019), The specific of the organizational culture in TMCP Bank, Finance Magazine, No. 706, the first term in 6/2019

4. K. Cameron, R. Quinn (2011). Diagnosing and changing organizational culture: based on competing for value framework, Third edition. USA: Jossey Bass.

5. Cuong, O. Q. and Ha, N. N and Danh, V. T. and Anh, N. P. T. and Lien, H. T. H (2016), To identify of factors made of the business culture at the export-import TMCP bank in Vietnam - Can Tho Branch. Science Magazine from Can Tho university, No. 42/2016

6. Hue, H. T. and Ha, D. T. (2019), The specific of the organizational culture in TMCP bank. Finance Magazine, No. 706, the first term in 6/2019

7. Uoc, T. M (2010), The urban culture with the growth of capital Ha Noi in the integration. Cultural Research Magazine, No. 03, page 49.

8. Uoc, T. M (2018), The fundamental matter about the business culture in the activity of the commercial bank, the international conference of science " to enforce the policy of the commercial bank towards Joint-stock Commercial Bank", Publisher, ISBN: 978-604-971-24-70, pages 33-37. 